\title{
Advances in the Development of Gravitational Water Vortex Hydraulic Turbines
}

\author{
Velásquez L. ${ }^{1, *}$, Chica E. ${ }^{1}$ and Posada J. ${ }^{2}$ \\ ${ }^{1}$ Grupo de Investigación Energía Alternativa (GEA), Facultad de Ingeniería, Universidad de Antioquia, Calle 70 No 52-21, Medellín \\ 050010, Colombia. \\ ${ }^{2}$ Grupo de Investigación e Innovación Ambiental, Facultad de Ingeniería, Institución Universitaria Pascual Bravo, Calle 73 No 73 A- \\ 26, Medellín 050010, Colombia
}

Received 15 March 2021; Accepted 26 June 2021

\begin{abstract}
The availability of energy has been essential for humanity, which increasingly demands more energy resources to cover its consumption and well-being. Due to the rapid depletion of fossil fuels and climate change, use of alternative energy sources such as non-conventional renewable energy sources is fundamental. Within non-conventional renewable energy sources, small-scale hydroelectric power is an excellent option in the generation of clean energy. Its development has a long useful life with more than 100 years and still with possibilities for new designs and technological adaptations. Among these new designs are the gravitational water vortex hydraulic turbines (GWVHTs). A GWVHT is a run-of-river (ROR) hydropower system that harnesses the kinetic and potential energy of an induced vortex. Its main advantage is the ability to generate energy in low ranges of head and flow. The GWVHT is a new turbine with an efficiency between 17 and $85 \%$, which still needs more research to optimize the geometry of the basin, inlet channel, and runner. This work presents a comprehensive analysis of various aspects of GWVHT such as modeling, optimum sizing, performance, and challenges to establish a starting point for further research. Until now, the studies have proved that the conical basins are better than the cylindrical basins, but they do not identify the dimensions of the geometry. With respect to the runner, the shape or number of blades has been varied, but the investigations show contradictory results.
\end{abstract}

Keywords: Gravitational water vortex hydraulic turbine, Non-conventional renewable energy sources, Water resources, Small hydroelectric power plants, Efficiency

\section{Introduction}

The intensive use of energy in different economic and social activities has allowed the acceleration of growth rates and demographic concentration [1]. By 2040, global energy demands are projected to increase by $30 \%$, while the population will grow from 7,400 to 9,000 million inhabitants [2]. The world must prepare to supply the demand for future energy.

Societies have supported their growth in an energy system based mainly on fossil fuels [3], but their rapid depletion along with global warming will affect humanity's lifestyle. The increased demands of energy have increased the researchers, governmental and non-governmental organization interest to work in the field of renewable energy sources [4].

Energy sources can be classified using several criteria: according to whether they are or not renewable, and according to their degree of availability: conventional or nonconventional. Renewable energy sources are those whose potential is inexhaustible as it comes from the energy that reaches the earth from solar irradiation or the gravitational attraction of other planets and satellites in the solar system. The main sources are solar, wind, hydraulic, tidal, geothermal, and biomass. Some of these are unpredictable because of their intermittent and stochastic nature. The main common features of renewable generation are variability, uncertainly, and location dependency. This variability is a reflection of the behavior of its primary source, such as irradiation and wind, which depends on the climatic, meteorological, and

*E-mail address: lisabel.velasquez@udea.edu.co.com ISSN: 1791-2377 @ 2021 School of Science, IHU. All rights reserved. doi:10.25103/jestr.143.01 hydrological phenomena. Nonrenewable energy sources are those in a limited amount in nature, such as those derived from petroleum (coal, diesel, natural gas, fuel oil, etc.), and uranium. Global energy demand is currently supplied by $70 \%$ with nonrenewable sources, while the remaining 30\% comes from renewable sources [3].

According to the second classification criterion, conventional energy sources are those that have significant participation in the energy balances of industrialized countries. This is the case of coal, oil, natural gas, hydraulic, and nuclear energy. Conversely, unconventional energy sources are those that do not have appreciable participation in the coverage of energy demand because they are not widely marketed. This is the case of small-scale solar, wind, tidal, biomass, and hydraulic energy.

There are many alternatives to produce energy from nonconventional renewable sources; one of them is the use of water energy. Hydropower is capable of responding to demand rapidly [5], making it the most flexible source available. The commercial operation of hydropower started in Grand Rapids, Michigan, in 1880. Where a turbine-produced electricity to power 16 brush-arc lamps at the Wolverine Chair Factory [6]. In 2019, with a global installed capacity of around 1,150 GW, the hydropower contributed $15.9 \%$ of the global electricity generation [7].

On a large scale, hydropower has a limited scope for expansion. Most of the major rivers, in developed countries, have one or more hydroelectric power plants, and in developing countries, large projects run into financial, environmental, and social obstacles. On a smaller scale, the generation of 
electricity in small hydroelectric power plants (SHP), projects that generate $10 \mathrm{MW}$ or less of power [8], does offer growth possibilities. SHP can take advantage of the relatively low flow rates of rivers with lateral capture without the need to create large reservoirs, conserving the ecological flows and limit the environmental effects of civil construction. SHP plants also supply electricity in remote areas and improve rural people quality of life. The global potential capacity of small-scale hydropower is $229 \mathrm{GW}$, however, it is estimated that only $34 \%$ has been used [9]. Europe is the continent with the highest percentage of use of its available potential capacity $48 \%$ (with a potential of $38.95 \mathrm{GW})$. Africa has a potential of $12.2 \mathrm{GW}$, but uses only $5 \%$.

Among the new technologies to produce electricity in SHP are the gravitational water vortex hydraulic turbines (GWVHTs). With efficiencies ranging from 17 to $85 \%$ [10], GWVHTs still have lower efficiencies than those reported by conventional systems with values that exceed 95\% [11]. Since its creation in 2006, a large amount of research has been conducted to understand how this system operates to improve its efficiency. Through a literature review, the frontiers of current knowledge about GWVHTs were identified with the aim of understanding the developments and to establish a starting point for future research. This study analyzed the strategies in developing the GWVHT: modeling approaches, design optimization and validations, in numerical and experimental studies.

\section{Gravitational water vortex hydraulic turbine}

A GWVHT is a run-of-river (ROR) hydropower system that harnesses the kinetic and potential energy of an artificially induced vortex in a basin with a central drain. A ROR hydropower system is a plant where the energy of the water is used when available. They do not have a water reservoir, thereby the flow varies according to the season. During rainy season, they develop their maximum power and excess water pass through. During the dry season, the power decreases, reaching zero in some rivers during the summer [12]. GWVHT operates at heads between 0.5 and $2.0 \mathrm{~m}$ and flow rates of $0.05-5 \mathrm{~m}^{3} / \mathrm{s}$, producing $0.2-5 \mathrm{~kW}$. Fig. 1 shows the GWVHT operation range compared to other hydraulic turbines, such as Pelton, Francis, Kaplan, cross flow, Archimedean screw, and Turgo turbines. GWVHTs are the turbines that require less volume flow rate and less head to operate.

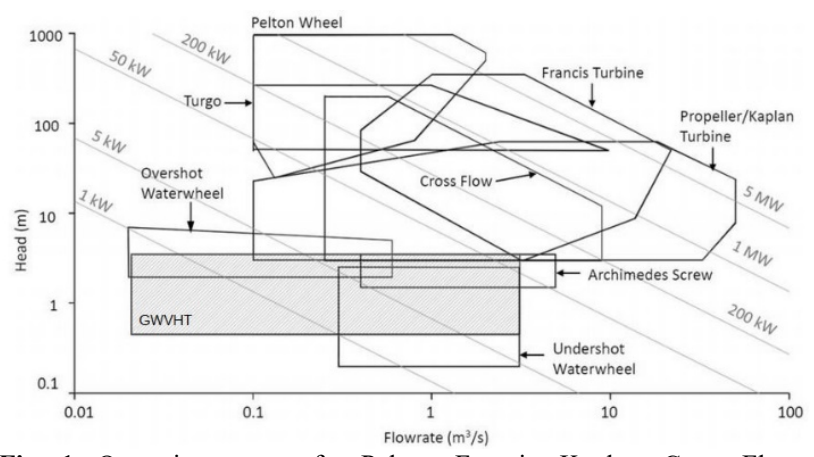

Fig. 1. Operating ranges for Pelton, Francis, Kaplan, Cross Flow, Archimedean screw, Turgo and GWVHT turbines. Adapted from [13].

GWVHT was created around 2006 by Austrian engineer Frank Zotlöterer while searching for ways to aerate inactive streams without external power [14-15]. In this system, the water is transported through an inlet channel until a basin. The velocity of the water is increased in a convergent section. An artificially induced gravitational water vortex is formed in the basin. Then, a vertical axis turbine extracts the energy of the vortex. Finally, the water returns to the river through a discharge [16].

Fig. 2 shows a diagram of a GWVHT, numbering each of its main elements: catchment, inlet channel, basin, runner, and discharge. The catchment not only allows water to be captured from the river but also controls the flow and level of suspended sediments. The inlet channel allows the water to enter the circulation basin in a tangential and controlled way, to facilitate the formation of the vortex.

In the world, 20 of these turbines have been installed. Europe is the continent with most facilities (14), followed by Oceania (3), South America (2) and Asia (1). Table 1 indicates the locations of the GWVHT, their generating power, volume flow rate, head, and efficiency.

The equations used for calculating the power of conventional hydraulic turbines are also used for calculating the power of GWVHT. Only a small change is incorporated into the net head $H_{n}$. The maximum available power of GWVHT is given by Eq. (1):

$$
P=\rho g Q\left(H_{n}-h_{1}-h_{2}-h_{3}\right)
$$

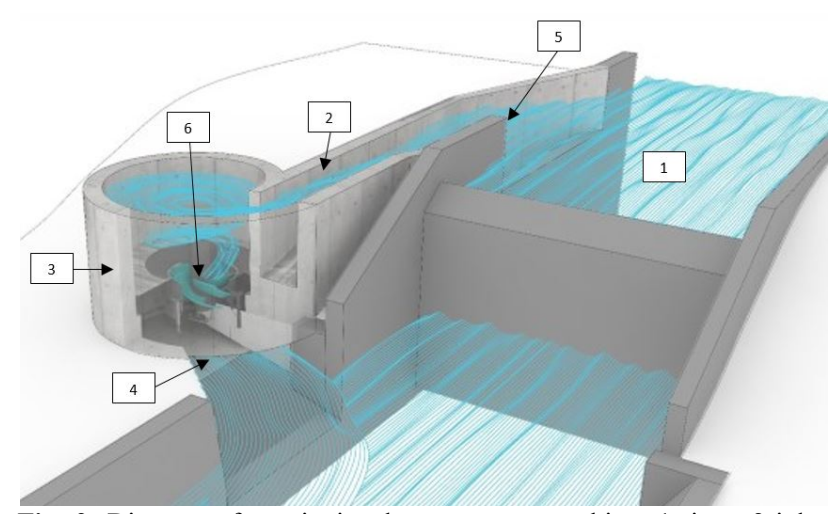

Fig. 2. Diagram of gravitational water vortex turbine: 1-river, 2-inlet channel, 3-circulation basin, 4-discharge, 5-catchment, and 6-runner [17].

where $\rho$ is the density of the fluid, $g$ the gravity, $Q$ the volume flow rate, $h_{1}$ is the head loss in the circulation basin, $h_{2}$ is the head loss in the inlet channel, and $h_{3}$ is the kinetic energy of the outflow [10]. The power generated by any hydraulic turbine is given by equation Eq. (2):

$P_{\text {out }}=T \omega$

where $\omega$ is the angular velocity, and $T$ is the torque. The hydraulic efficiency of the vertical axis turbine $\eta$ is determined by equation Eq. (3):

$\eta=\frac{P_{\text {out }}}{P}=\frac{T \omega}{\rho g Q\left(H_{n}-h_{1}-h_{2}-h_{3}\right)}$

The turbines installed in the world have efficiencies ranging from 17 to $85 \%$, head values between 0.6 and $2.0 \mathrm{~m}$, and output powers between 0.01 and $20.0 \mathrm{~kW}$ [10]. Austria has 10 GWVHTs; four of these installations have around the same power, between 4.0 and $5.0 \mathrm{~kW}$, with efficiencies of $58 \%$ for $4.0 \mathrm{~kW}$ turbines, $60 \%$ for the $4.4 \mathrm{~kW}$ turbine, and $61 \%$ for the $5.0 \mathrm{~kW}$ turbine. These values indicate, at least for this group, that the greater the power of the system, the greater its efficiency. From the 20 installations, the turbine with the 
highest efficiency $(85 \%)$ is installed in Indonesia and generates $15 \mathrm{~kW}$. Two more turbines generate the same power: Switzerland and Chile. These turbines report efficiencies of only 46 and $57 \%$, respectively. The lowest efficiency turbine (17\%) also corresponds to the lowest power turbine $0.01 \mathrm{~kW}$, while the highest power turbine $(20.0 \mathrm{~kW})$ reports an efficiency of $68 \%$. No clear pattern of efficiency behavior is identified.

GWVHTs have a lower efficiency than conventional turbines. Therefore, research has focused on optimizing the geometry to increase their hydraulic efficiency. Different basins and runners have been used to increase the tangential velocity and form a stable vortex. For the design of the circulation basin and inlet, two geometries are normally used: cylindrical and conical basin both with tangential inlet and with central discharge. These geometries and their main dimensions are shown in Figs. 3 and 4. For the runner, the original design of Frank Zotlöterer is used: cylindrical runner with a plurality of blades uniformly distributed over the circumference. The studies have been focused on three fields: numerical, numerical-experimental, and experimental.

Table 1. GWVHT installed in the world. Modified from [10].

\begin{tabular}{l|c|c|c|c}
\hline Location & Head [m] & Flow rate [m/s] & Power [kW] & Efficiency [\%] \\
\hline Austria & 1.5 & 0.90 & 8.3 & 63 \\
Austria & 0.9 & 0.70 & 3.3 & 53 \\
Austria & 1.5 & 0.50 & 4.4 & 60 \\
Austria & 1.4 & 0.50 & 4.0 & 58 \\
Austria & 1.4 & 0.50 & 4.0 & 58 \\
Austria & 1.4 & 0.60 & 5.0 & 61 \\
Austria & 1.2 & 1.20 & 7.5 & 53 \\
Austria & 1.8 & 1.00 & 10.0 & 57 \\
Austria & 1.6 & 2.00 & 18.0 & 57 \\
Austria & 1.0 & 0.90 & 4.6 & 52 \\
Germany & 1.2 & 1.50 & 6.0 & 51 \\
Switzerland & 1.5 & 1.00 & 10.0 & 68 \\
Switzerland & 1.5 & 2.20 & 15.0 & 46 \\
Belgium & 2.0 & 0.25 & 3.0 & 61 \\
Australia & 0. & 0.11 & 0.35 & 54 \\
Australia & 0.6 & 0.01 & 0.01 & 17 \\
Australia & 0.8 & 0.05 & 0.18 & 49 \\
Peru & 1.2 & 1.20 & 3.5 & 29 \\
Chile & 1.5 & 1.80 & 15.0 & 57 \\
Indonesia & 1.5 & 1.20 & 15.0 & 85 \\
\hline
\end{tabular}

\subsection{Numerical studies}

In 2010, Mulligan and Hull [18] made the oldest publication on GWVHT. They determined the optimal diameter of the discharge for a cylindrical basin. The authors determined that for optimal vortex formation, the diameter of the discharge was between 14 and $18 \%$ of the diameter of the basin $(d / D=0.14-0.18)$. They also proposed that the vortex height varies linearly with discharge diameter.

Two years later, Marian et al. [19] introduced the use of conical basins for GWVHT and determined the effects of basin shape on turbine performance comparing the cylindrical and conical geometries. Marian et al. [19] modeled the flow of water in the turbine with and without runners. To simulate the flow through the basins, they modeled the GWVHT in SolidWorks. The simulations were developed in Comsol. For the first case, they excluded the runner; the water flow formed a vortex that extended to the discharge. In the second case, the runner was included. Here, the vortex no longer extended to the discharge because eddies formed near the turbine blades. A helical turbine with multiple stages was the turbine chosen for this second analysis because the authors affirmed that the best turbine to extract the energy was a helical turbine with hydrofoil profile. Marian et al. [19] concluded that the height of the vortex influences the extraction of the energy from the flow, thus to increase the efficiency, it is necessary to extend the vortex to the discharge.

Dhakal et al. [20] studied the effect on conical basin in the vortex formation. They excluded the runner. For a given volume flow rate and head, the authors changed the diameter $(D)$ and height of the basin $(H)$, and the length $(L)$ and height (h) of the inlet channel. The variation in length and height of the channel has not been considered until now.

Dhakal et al. [20] developed different basin and channel configurations using SolidWorks, and then the models were simulated in Ansys Fluent. The results showed that there is a dominant effect of basin diameter on the tangential velocity in the vortex (Fig. 5). When the basin diameter increases, the tangential velocity increase until a maximum velocity. The maximum velocity $(0.52 \mathrm{~m} / \mathrm{s})$ occurred when the diameter was $510 \mathrm{~cm}$. After this point, if the basin diameter increases, the velocity decreases. For the channel, they concluded that as its height increases, the tangential velocity also gradually increases until reaching a constant velocity close to $0.50 \mathrm{~m} / \mathrm{s}$. The analysis suggests that the diameter of the basin is an important characteristic that must be taken into account for the design of GWVHT. Varying the diameter changes the value of the velocity and vortex height.

Dhakal et al. [21] conducted a study to establish the optimal position of a runner drawn in SolidWorks and numrically simulated in Ansys Fluent. The geometries used are shown in Fig. 6. The maximum tangential velocity was $0.6 \mathrm{~m} / \mathrm{s}$ for the conical basin, and $0.525 \mathrm{~m} / \mathrm{s}$ for the cylindrical basin. Both velocities were reached at a distance of $0.875 \mathrm{~m}$ measured from the surface of the basin, and for the same inlet velocity of $0.1 \mathrm{~m} / \mathrm{s}$. The results indicate that conical basins are better than cylindrical ones because higher tangential velocity produces greater output-generated power, and that the best position of the runner inside the basin corresponds to a height of between 65 and $75 \%$ of the basin height $(H)$ measured from the top. 


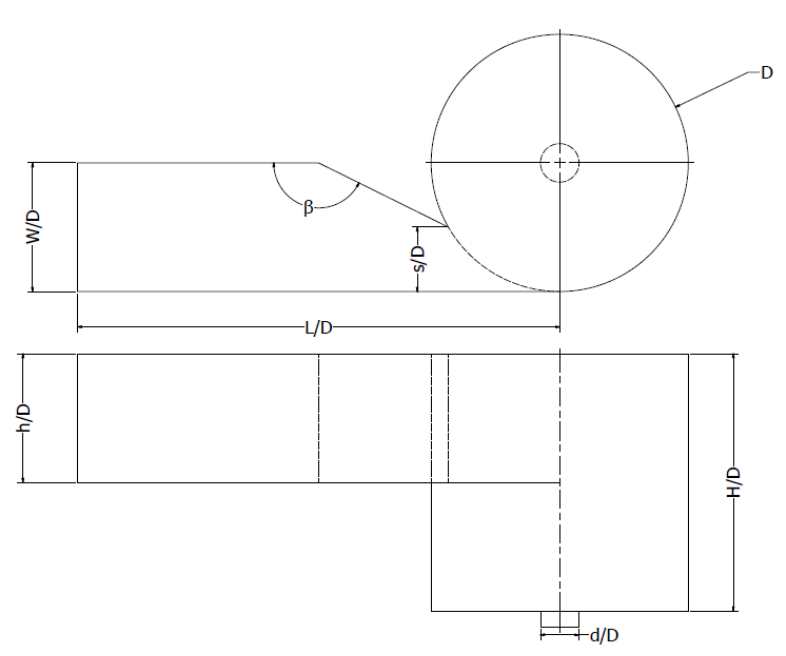

Fig. 3. Main dimensions for the cylindrical basin.

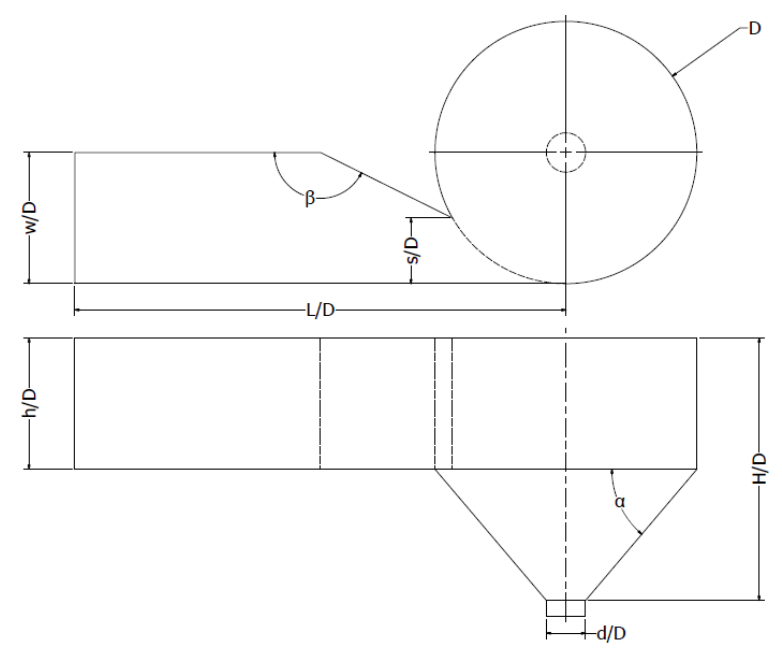

Fig. 4. Main dimensions for the conical basin.

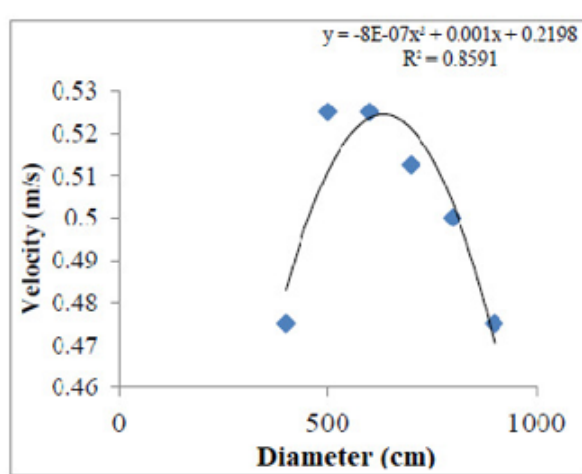

Diameter (cm)

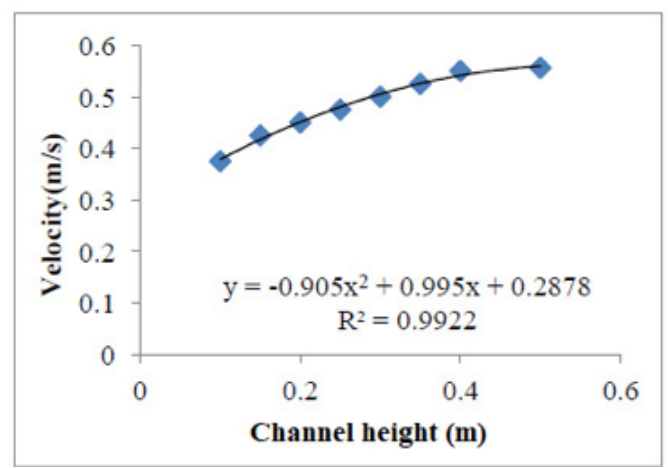

Fig. 5. a) Effect of basin diameter vs. vortex velocity and b) Effect of channel height vs. vortex velocity [20].
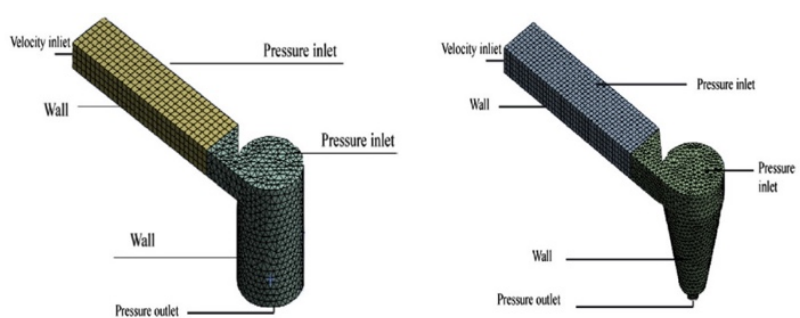

Fig. 6. Boundary conditions for cylindrical and conical basins [21].

Sreerag et al. [22] studied the effect of discharge diameter on the turbine efficiency as a function of tangential velocity. The computational analysis was executed using ANSYS Fluent 14.5 and allowed to find the tangential and radial velocities at different locations within the velocity field. They concluded from the analysis that, for a turbine with a conical basin of $1 \mathrm{~m}$ in diameter, $1 \mathrm{~m}$ in height and with a cone angle of $14^{\circ}$, a discharge with a diameter of $30 \%$ of the diameter of the basin $(d / D=0.3)$ provides the highest tangential velocity and therefore the maximum output power. The ratio between the diameter of the basin and the discharge hole is the double than the ratio proposed by Mulligan and Hull [18].

Chattha et al. [23] investigated different basin design configurations for a GWVHT using CFD with the aim of increasing tangential velocity in the vortex core. For their study, they used a cylindrical basin with a discharge orifice in the center and varied the diameter of the basin, the diameter of the discharge, and the inlet flow. They found that to increase the magnitude of the tangential velocity by up to $15 \%$, it was necessary for a vortex to be generated that went from the free surface of the basin to the discharge orifice. As indicated by Marian et al. [19] in their early investigations. The best way to generate the vortex is to increase the outlet diameter keeping all the other parameters of the basin constant: diameter and height. An increase in the discharge diameter represents an increase in the Froude number, which increases the value of the critical immersion. When the critical immersion increases, there is a greater tendency toward the formation of the vortex.

Thapa et al. [24] studied the effect of the inlet channel on vortex formation in a GWVHT. ANSYS Fluent was used for numerical analysis. In the experiment, four input geometries were taken for the channel: triangular, rectangular, circular, and curved, Fig. 7, these figures are viewed from the top. Their study showed that the vortex formed by the use of an entrance channel with triangular geometry is more efficient, since it tends to produce a symmetrical vortex pattern, which causes a smaller radial force. Radial steering forces are responsible for creating bending moments on the turbine shaft, reducing the efficiency of the turbine. The study also showed that the rectangular inlet channel produces a symmetrical vortex but high-pressure distribution, implying that the rectangular inlet geometry can be effective on low heads, but can cause turbine shaft failure in heads of magnitude superior due to the generation of unexpected bending moments on the shaft. This was the first investigation to study other geometries for the inlet channel, as previous studies had used rectangular geometries and tried optimizing its dimensions: height $(h)$, width $(w)$, and length $(L)$. 

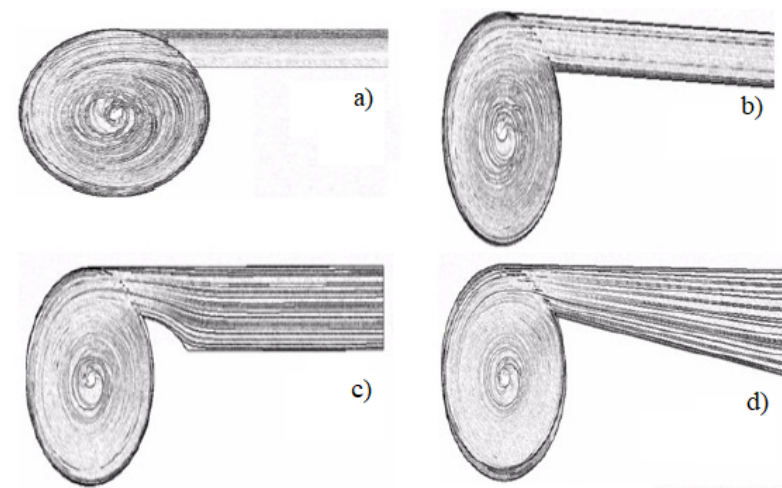

Fig. 7. a) Channel with circular geometry, b) Channel with curved geometry, c) Channel with rectangular geometry, and d) Channel with triangular geometry [24].

Rehman et al. [25] studied three types of tangential inlet channel: horizontal channel, $30^{\circ}$ and $60^{\circ}$ inclined channel using a conical basin, see Fig. 8. The results show that the highest tangential velocity was achieved when the channel was inclined $60^{\circ}$. That increase in velocity can be attributed to the change of potential head to dynamic head. For the simulations, ANSYS Fluent was used, using a constant water entry velocity of $3 \mathrm{~m} / \mathrm{s}$ in each model. The authors did not elaborate on the simulation settings.
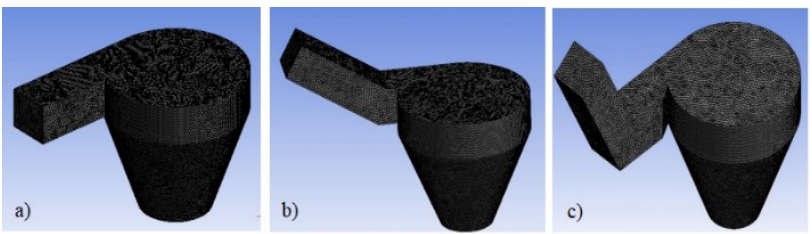

Fig. 8. Model with inlet rectangular passage of a) $0^{\circ}$ b) $30^{\circ}$ and c) $60^{\circ}$ [25].

Khan et al. [26] studied the effects of basin diameter (0.4$0.8 \mathrm{~m})$, discharge to basin diameter ratio $d / D(0.13-0.17)$, basin height to diameter ratio $H / D(0.5-1.5)$, inlet channel width ratio $w / D(0.1-0.5)$, inlet channel depth ratio $h / D$ $(0.1-0.5)$, and inlet velocity $(0.1-0.6 \mathrm{~m} / \mathrm{s})$ on vortex formation and tangential velocities. They used Ansys CFX to discretize the governing equations using a finite-volume approach. The results show that the configuration with a fully developed air core is the most suitable for increasing the efficiency of the system. When a basin with a large diameter is used, the vortex height decreases. An increase of $w / D$ increases the mass flow, which causes the water height to rise until the overflow from the upper walls of the basin occurs. Increasing the ratio $d / D$ allows more water to flow out of the basin, observing a reduction in the vortex height in the basin.

Wardhana et al. [27] analysed the behavior of propeller type impellers when positioned in GWVHT systems. They made variations in the shape and length of the blade chord, as well as in the number of blades. The results indicate that the number of blades is inversely proportional to the efficiency; they also concluded that the shape of the blades is more efficient when twisted and they selected the rotors with three blades as the most efficient study, with an efficiency of $54.4 \%$.

Havaldar et al. [28] compared two geometries for tangential inlet channel to GWVHT: straight and curve, see Fig. 9. The models were made in SolidWorks. The meshing and simulations were done in ANSYS Fluent. They found that the average velocity in a curved inlet channel was greater than that of the straight inlet channel. A greater velocity implies that the energy extraction is greater. The authors did not elaborate on the simulation settings.

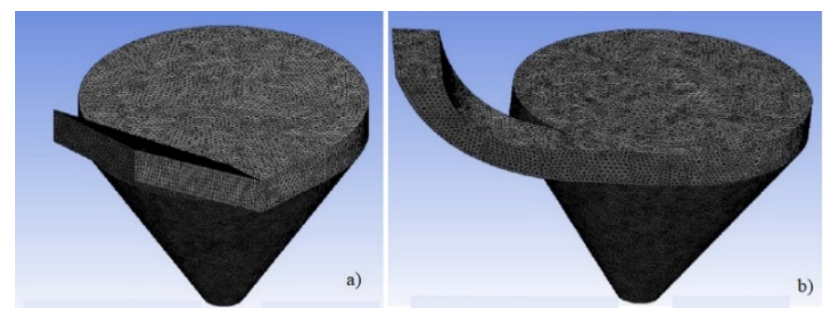

Fig. 9. Inlet channel Models: a) straight and b) curve [28].

Two inlet channels and two basin geometries of a GVWH were analyzed in Ansys Fluent by Velasquez et al. [29]. The velocity and vortex height were calculated and compared for four geometries: (I) cylindrical basin with a tangential inlet, (II) cylindrical basin with a wrap-around inlet, (III) conical basin with a tangential inlet and (IV) conical basin with a wrap-around inlet. This was the first study where two geometries for the inlet were compared: a regular tangential inlet and a wrap-around inlet, see Fig. 10a). For the simulation, the Volume of Fluid (VOF) method was implemented with the $\mathrm{k}-\varepsilon$ turbulence model. For all simulations, an inlet velocity of $0.1 \mathrm{~m} / \mathrm{s}$ was used. The results reveal that the conical basin is better than the cylindrical one because the conical produced a more symmetric vortex compared with that generated by the cylindrical basin. Geometry (IV) provided the largest tangential velocity (1.55 $\mathrm{m} / \mathrm{s}$ ) at a radius of $0.22 \mathrm{~m}$ (Fig. 10b). Knowing the location of the highest velocity allows to identify the installation point of the runner, where a greater energy extraction is possible.

\subsection{Experimental studies}

Dhakal et al. [30] designed, manufactured, and tested 3, 6, and 12-blade runners for a GWVHT. The runners were tested in cylindrical and conical basins to compare the efficiency of the runners in both type of setup. For the cylindrical basin, 12 tests were conducted by changing the runners and their position in the basin. Dhakal et al. [30] indicated that the best position for placing the turbine is the lowest position, that is, the position closest to the discharge. Since it is where the vortex has the highest velocity. They also found that the efficiencies were higher for runners with fewer blades. The conical basin, with 12-blade runner, provided a maximum efficiency of $29.63 \%$ for the position closest to the discharge. This efficiency was significantly higher than the efficiency obtained from all cylindrical basins. The higher efficiency of this conical basin is product to the higher vortex height. Since the three and six blade runners were not evaluated in the conical basin, it is not possible to state that cylindrical basins with fewer blades provide greater efficiency.
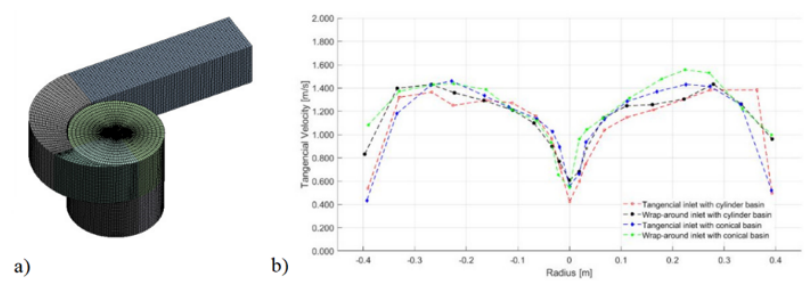

Fig. 10. a) Wrap-around inlet with cylindrical basin, and b) Tangential velocity distribution [29].

Sritram et al. [31] studied the effect of the blade material on the efficiency of the GWVHT. The materials tested were 
stainless steel and aluminum. Two impellers of five curved blades were manufactured and tested with a flow rate of 3.63, $2.96,2.31,1.61,1.33$, and $0.68 \mathrm{~m}^{3} / \mathrm{min}$, and an electrical load of $100,80,60,40,20 \mathrm{~W}$, respectively. The results showed that the maximum efficiency of the aluminum and steel was $34.79 \%$ and $33.56 \%$, respectively. Fig. 11 shows the efficiency at different loads for both materials. The momentum and the electricity production of the aluminum turbine were higher than that of the steel turbine at the maximum flow rate. This result showed that the lightweight of the turbine increases the momentum and efficiency. Sritram et al. [32] were the first ones to evaluate different materials for the runner.

Power et al. [32] conducted an experimental study to determine the best-operating conditions for a GWVHT. They tested different blades in size and number at various flow rates. They also recorded the turbine rotational velocity, and the vortex height for each configuration. The efficiency, input and output power were compared. The turbine used consisted of a cylindrical basin, $0.7 \mathrm{~m}$ height, and $0.5 \mathrm{~m}$ in diameter, with a central outlet hole of $0.025 \mathrm{~m}$. Turbines with two and four flat blades with different widths, heights, and thicknesses were tested. Power et al. [32] reported a maximum efficiency of $15.1 \%$ for the four blades with the largest surface area at a flow of $0.65 \mathrm{~L} / \mathrm{s}$ and a head of $0.9 \mathrm{~m}$. This indicates that the efficiency increases when the number of blades increases from two to four. This conclusion contradicts what was said by Dhakal et al. [30], who indicated that fewer blades in cylindrical basins increase efficiency. The opposing findings indicate that there could be an optimal number of blades, and further studies are required.

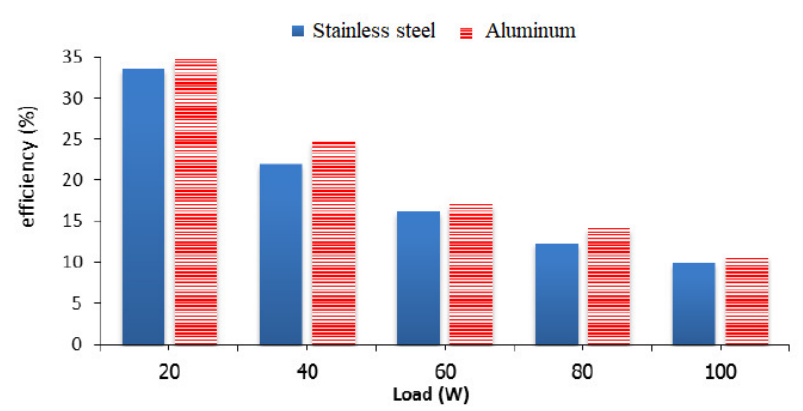

Fig. 11. Efficiency of the turbines for a water flow of $3.63 \mathrm{~m}^{3} / \mathrm{min}$ [31].

Ayala et al. [33] designed and implemented an electric power generation system based on a GWVHT in LojaEcuador. The system can be installed directly in irrigation channels or rivers, without major civil works. The generation unit called UTG (Underwater Turbine Generator) is made up of a Kaplan turbine, a cylindrical basin, and a siphon evacuation to gain potential energy. According to field measurements, the UTG system has a generation capacity of $150 \mathrm{~W}$ and can supply electrical energy to connected loads with a plant factor of $60 \%$ with a flow rate of $0.05 \mathrm{~m}^{3} / \mathrm{s}$ and a head of $1.0 \mathrm{~m}$.

The effects of water pressure and the length and number of blades on a GWVHT were experimentally studied by Rahman et al. [34]. They designed and tested a cylindrical basin GWVHT with three and six blade runners to determine the efficiency, see Fig. 12. Experimental results revealed that the tangential velocity of the vortex was higher for a $0.12 \mathrm{~m}$ head and the maximum efficiency, achieved with the 3-blade runner and an outlet diameter of $0.027 \mathrm{~m}$, was $43 \%$. They also found that the maximum rotational velocity does not generate the highest efficiency. This research supports the conclusion of Dhakal et al. [30], a runner with fewer blades is more efficient.

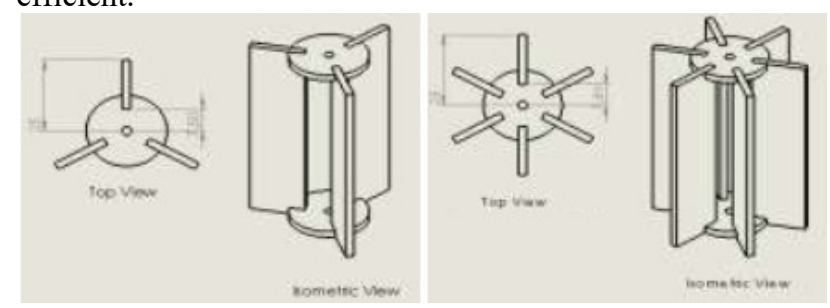

Fig. 12. Runners for a GWVHT [34].

Wichian et al. [35] experimentally analyzed the effects on the efficiency of the installation of baffle plates at the bottom and top of the runner blades for a GWVHT. A baffle plate is a metal plate used to direct or restrain the flow of a fluid. For the study, they used a cylindrical basin plant of $1 \mathrm{~m}$ in diameter and $1 \mathrm{~m}$ high. The water flow was between 0.04 $0.06 \mathrm{~m}^{3} / \mathrm{s}$ and the basin diameter was $0.2 \mathrm{~m}$. Five models of 5-blade runners with deflector plates were tested, see Fig. 13. The proportion of the plates was $0,25,50,75$, and $100 \%$, in relation to the total area of the blades. Model 3, with a ratio of $50 \%$, was the model that produced the highest torque, thereby increasing the efficiency by $4.12 \%$ and torque by $10.25 \%$, compared to the model without plate deflectors. The latter ones generated an average torque of $33.93 \mathrm{Nm}$ and an efficiency of $31.49 \%$. Large baffle plates, 75 and $100 \%$ ratio, produce too much inertia and significantly reduce torque and efficiency.

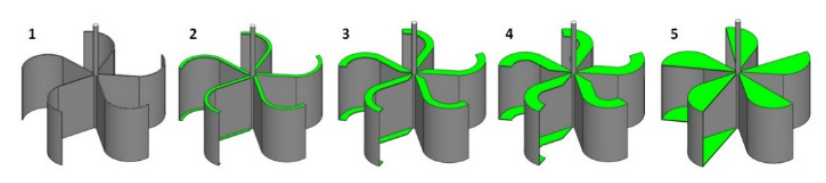

Fig. 13. Runners with baffle plates [35].

The effects of the rotational velocity and the shape of the blades on the performance of a GWVHT were investigated by Kueh et al. [36]. Two turbines with curved and flat blades were compared. Both turbines showed a similar rotational velocity under no-load conditions, suggesting that the geometry of the turbine does not have a significant effect on this velocity. The turbine with flat blade had a maximum efficiency of $21.63 \%$ at $3.27 \mathrm{rad} / \mathrm{s}$, while the turbine with curved blade showed an efficiency of $22.24 \%$ at $3.56 \mathrm{rad} / \mathrm{s}$. Both tests used a head of $5 \mathrm{~m}$ and a mass flow rate of $15 \mathrm{~kg} / \mathrm{s}$. When the load is applied, the curved shape of the blades reduce disturbances in the vortex and therefore provided a better performance. The runners used in the study had four blades.

Rahman et al. [37] used a laboratory scale GWVHT to estimate the effect of the flow rates and inlet channel (Penstock) in the efficiency. They found that the efficiency increases in a polynomial pattern when flow rates increase from $5.6 \mathrm{~m}^{3} / \mathrm{h}$ to $8.8 \mathrm{~m}^{3} / \mathrm{h}$. The conclusion is valid for channels with different lengths of the channel $(\boldsymbol{L})$ and feed width (S); see Fig. 14. The performance of penstocks D, E, and $\mathrm{F}$ was similar. This means that $\boldsymbol{L}$ has no effect on efficiency. Contrarily, $\boldsymbol{S}$ has a significant effect on the performance of GWVHT. Penstocks B and C with $0.065 \mathrm{~m}$ and $0.090 \mathrm{~m}$, respectively, reported lower efficiencies. Reducing the value of $\boldsymbol{S}$ will increase the tangential velocity, 
hence increasing the output power and improving the efficiency.

\begin{tabular}{|c|c|c|}
\hline Inlet channel & L $(\mathrm{m})$ & $\mathrm{S}(\mathrm{m})$ \\
\hline $\mathrm{A}$ & 0.513 & 0.040 \\
\hline $\mathrm{B}$ & 0.513 & 0.065 \\
\hline $\mathrm{C}$ & 0.513 & 0.090 \\
\hline $\mathrm{D}$ & 0.385 & 0.040 \\
\hline E & 0.257 & 0.040 \\
\hline F & 0.128 & 0.040 \\
\hline
\end{tabular}

a)

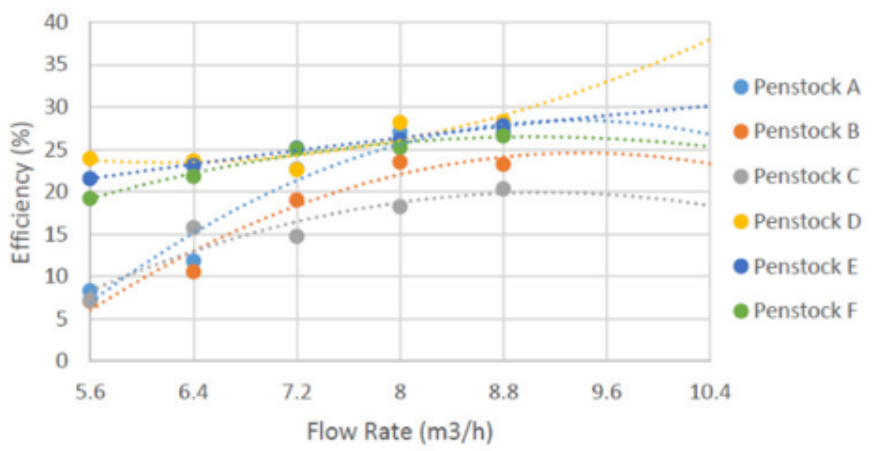

b)

Fig. 14. a) Inlet channel dimensions and b) Efficiency with different inlet channels [37].

Srihari et al. [38] studied five types of conical basins with nozzles that intensify the vortex. These nozzles are highlighted in red box in Fig. 15a). The same pump was used to fill the basin and the intensifier nozzles; they used ball valves to adjust the flow in the intensifier nozzles. The authors unspecified the pressure reaches in the nozzles. The results indicated that the turbine with six nozzles of $50 \mathrm{~mm}$ in diameter, separated $150 \mathrm{~mm}$ from the upper surface of the basin, presented an increase in power of $54.42 \%$. This represents an increase in the efficiency of $54.41 \%$, with respect to the turbine studied by Dhakal et al. [21]. The nozzles strengthen the formation of the vortex, and therefore increase the efficiency of the turbine.

Ullah et al. [39] studied the performance of a multi-stage GWVHT with conical basin. Rotational velocity, momentum, and efficiency were evaluated under different load conditions. The authors found that runners with tilted blades are best suited for the position near the bottom of the discharge, while cross-flow blades are recommended in the top position.

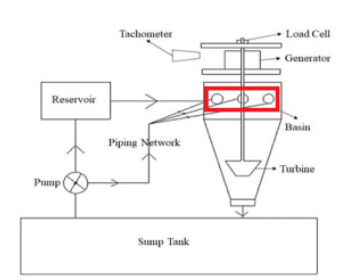

a)

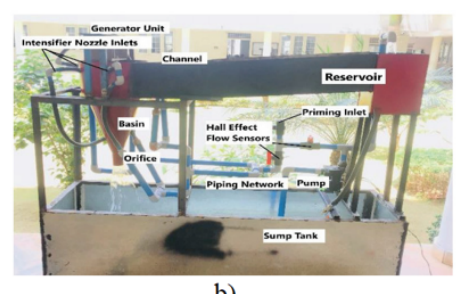

b)
Fig. 15. Gravitational water vortex turbine: a) Schematic of experimental setup and b) Fabricated experimental setup [38].

\subsection{Numerical and experimental studies}

Continuing the numerical study with by Marian et al. [19], Marian et al. [40] experimentally investigated the characteristics of the vortex in the presence of runners in a conical basin. The experimental set-up was conducted using two tanks that were connected through a closed circuit of pipes. Four basins with various heights $(H=0.1,0.15,0.2$, and $0.25 \mathrm{~m}$ ) were tested with cone angles $(\alpha)$ of $54.04,37.56^{\circ}$, $28.61^{\circ}$, and $23.06^{\circ}$, respectively. All of them with a diameter $D$ of $0.12 \mathrm{~m}$ and a discharge diameter $d$ of $0.018 \mathrm{~m}$. Three runners with four flat blades were installed in these basins at different depths, see Fig. 16. The highest efficiency was obtained when the turbine was located as close as possible to the discharge. An increase in the cone angle decreases the outflow, which generates an overflow through the borders of the basin.

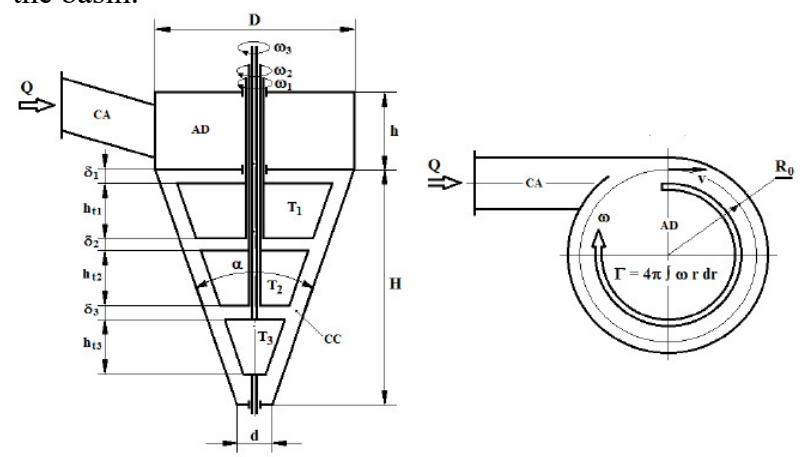

Fig. 16. Schematic of a GWVHT [40].

In turn, Wanchat et al. [41] conducted a numerical and experimental study on how the outlet diameter, the inlet flow, and vortex height affects the velocity field. Flow behavior was simulated using Ansys. The SIMPLE method for the pressure and velocity coupling was adopted. The model used was a cylindrical basin with $1 \mathrm{~m}$ in diameter and a $1 \mathrm{~m}$ in height, with an outlet of variable diameter $(0.1<d<0.4 \mathrm{~m})$. A velocity of $0.1 \mathrm{~m} / \mathrm{s}$ was imposed as inlet velocity condition. Experimental and theoretical models showed that for outlet diameters less than $0.2 \mathrm{~m}$, the angular momentum of the vortex was not enough to turn the turbine. This was because the water entering the system was greater than the water leaving. Alternatively, when the outlet diameter was equal to or greater than $0.4 \mathrm{~m}$, the vortex height was low and it failed to generate enough torque to move the turbine. The maximum power was $60 \mathrm{~W}$ for a model with an output diameter of 0.2 $\mathrm{m}$ that reached an efficiency of $30 \%$. This diameter corresponds to $20 \%$ of the basin diameter. Unlike the study by Marian et al. [19], this research excluded the effects of the runner in the velocity field, but they also concluded that the vortex height is an important parameter for power generation. Two configurations with different discharge diameters were studied numerically and experimentally by Kueh et al. [42]. The basin used for both configurations was a cylindrical basin with a tangential inlet. The XFlow 2013 software, which uses a Lagrangian approach to solve the Navier-Stokes equations, was used for the numerical study. The height of the vortex was the same in the experimental and numerical model for the smallest discharge diameter $(d=0.02 \mathrm{~m})$. While for the largest diameter $(d=0.025 \mathrm{~m})$, there were significant differences in the vortex height. A very large outlet diameter 
implies greater turbulence, which generates greater errors in the computational solution. The adequate selection of the turbulence model allows to find a numerical solution reflecting the behavior of the phenomenon.

Shabara et al. [43] optimized a GWVHTS using Ansys Fluent 14.0. The cylindrical basin had a height of $100 \mathrm{~cm}$, a diameter of $100 \mathrm{~cm}$, and an outlet diameter of $20 \mathrm{~cm}$. Eight curved blade runners were included in the simulations. Additionally, experimental tests were performed to validate the results. The maximum efficiency (around 40\%) occurs when the turbine rotates between 28 and $38 \mathrm{rpm}$. The numerical results compared favorably with the experimental results. The position of the runner is not specified in this study.

Gautam et al. [44] studied numerically and experimentally the effect of the addition of a second runner on the efficiency of a GWVHT with conical basin, just as Marian et al. [19] did. For this study, 3- and 6-blade runners were designed. The flow domain was modeled in Catia followed by simulation in Ansys Fluent 16.2. Three-dimensional steady state simulations were performed. The dimensions of the basin, the channel, the main runner and the location of the secondary runners were the same for the three studies. Gautam et al. [44] reported an efficiency of $78.65 \%$ for a turbine with a type III secondary runner, see Fig. 17 . This represents an increase in efficiency of approximately $6 \%$ compared to a single runner. The authors used a brake drum dynamometer, and a digital tachometer to get the efficiency. A current meter was used for measuring the inlet velocity, which was in turn used for calculating the flow rate. This study does not specify the shape or number of blades of the main runner.
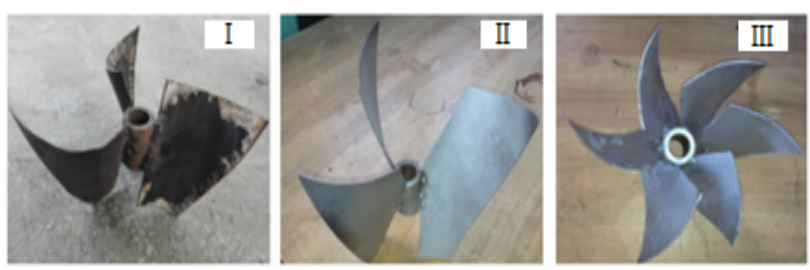

Fig. 17. Runners [44].

Nishi et al. [45] predicted the efficiency of a GWVHT. The authors performed a transient numerical analysis. The governing equations were discretized by the Finite Volume Method (FVM) using Ansys CFX 15.0. They used the Volume of Fluid method (VOF), which allows flow that has a clear interface between two phases. Water and air were the working fluids. The Shear Stress Transport model (SST) was selected as the turbulence model. Its final mesh had $2.2 \times 10^{6}$ elements. The boundary conditions established were mass flow at the inlet, relative static pressure of $0 \mathrm{~Pa}$ on the upper surfaces of the basin and the inlet channel, non-slip condition for the walls, and outlet pressure at the discharge. They performed experiments in a cylindrical basin with a 490$\mathrm{mm}$ diameter, a discharge of 100-mm diameter, and a turbine with 20 blades. The runner geometry resembles the geometry of a cross-flow turbine. The numerical and computational results showed that the methodology selected was right, since the experimental and computational values of momentum and efficiency coincided with each other, see Fig. 18.

Dhakal et al. [46] conducted an experimental and computational investigation of a runner for a GWVHT using a conical basin. This study focused on optimizing the runner to improve system efficiency. CFD analysis was performed on three runners with curved, twisted, and straight blade profiles, all of them with six blades, see Fig. 19. Ansys CFX was used to analyze the flow through the turbine. Numerical analysis showed that the curved blade profile obtained the maximum efficiency ( $82 \%)$. This profile is the most efficient, followed by the twisted blade, $63 \%$, and the runner with straight blades with $46 \%$. The experimental analysis was conducted with the best runner found in the numerical study. Using a volume flow rate of $0.004 \mathrm{~m}^{3} / \mathrm{s}$ and $0.5-\mathrm{m}$ head, the maximum efficiency was $71 \% .9 \%$ lower than the predicted by the numerical analysis. The difference between the experimental tests and the computational analysis was mainly attributed to mechanical losses, leakages, the non-ideal construction of the channel, the friction of the basin surface with the fluid, and the increase in the rotational velocity of the turbine. This research is the one that reports the highest efficiency so far.

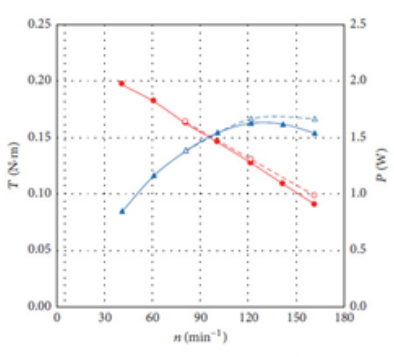

a) b) $\underset{\rightarrow-\eta(\text { Exp) }}{\rightarrow} \rightarrow H$ (Exp)

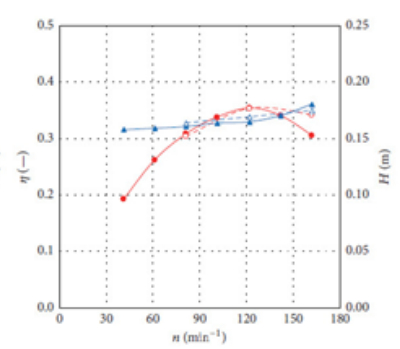

Fig. 18. Turbine performance: a) Torque and power vs. rotational velocity and b) Efficiency and effective head vs rotational velocity [45].
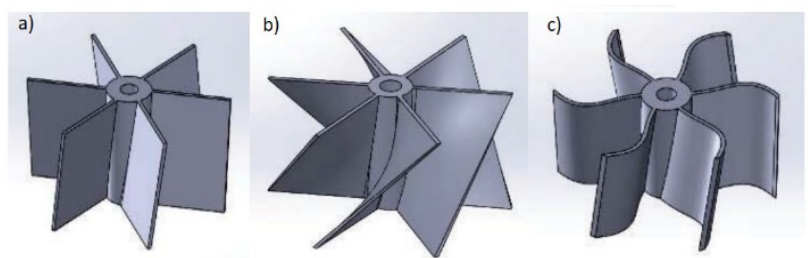

Fig. 19. Runners: a) straight blades, b) twisted blades, and c) curved blades [46].

The most recent investigation about GWVHT was made by Nishi et al. [47]. The authors conducted a numerical and experimental study using a cylindrical basin with a diameter of $490 \mathrm{~mm}$ and a discharge with a diameter of $100 \mathrm{~mm}$. For the 3D unsteady flow numerical analysis, they used Ansys CFX 15.0 with the VOF method. They found that the net head and the turbine efficiency increased as the flow rate increased. Fig. 20a) shows the experimental apparatus and Fig. 20b) shows the comparison between the numerical (or calculated) and experimental values of the efficiency. The highest efficiency was $55 \%$ when the flow rate and net head were $0.00379 \mathrm{~m}^{3} / \mathrm{s}$ and $0.16 \mathrm{~m}$, respectively. The highest efficiency represented an increase of $5.3 \%$. Although the authors concluded that increasing the flow rate increases the efficiency, there must be a limit to the increase in flow rate. An excess flow prevent proper vortex formation or cause flow spillage.

\subsection{Summary of results}

Tab. 2 shows the summary of the numerical and experimental results around GWVHT. The tables highlight the type of investigation, whether or not a runner is used, the type of basin, and the main findings. Tab. 3 shows only numerical studies and the parameters used to conduct the simulations, such as computational models used, turbulence model, and solution schemes. 

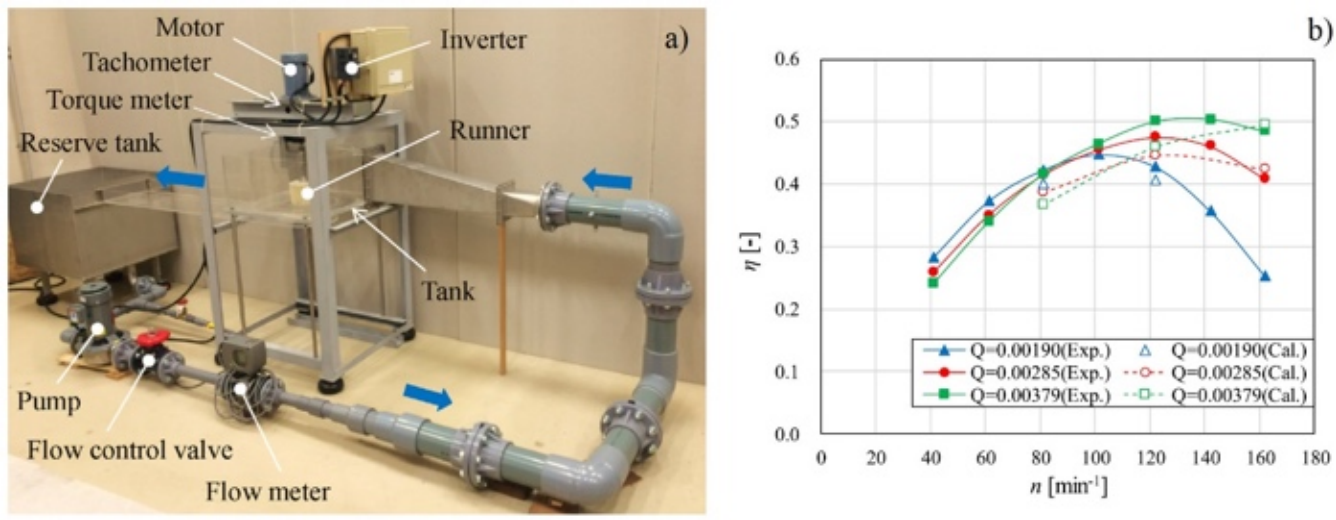

Fig. 20. a) Experimental apparatus and b) Turbine efficiency. Volume flow rate is expressed in $\mathrm{m}^{3} / \mathrm{s}$ [47].

Table 2. Numerical and experimental studies and their main findings.

\begin{tabular}{|c|c|c|c|}
\hline Author & Method & $\begin{array}{l}\text { With or without } \\
\text { runner/Type of basin }\end{array}$ & Results \\
\hline [18] & Numerical & $\begin{array}{l}\text { With runner/Cylindrical } \\
\text { basin }\end{array}$ & $\begin{array}{l}\text { Optimal vortex formation when outlet diameter is } 14 \% \text { - } \\
18 \% \text { of the basin diameter }\end{array}$ \\
\hline [19] & Numerical & $\begin{array}{l}\text { With and without } \\
\text { runner/Conical basin }\end{array}$ & $\begin{array}{l}\text { To increase efficiency is necessary to keep the vortex up } \\
\text { to the outlet }\end{array}$ \\
\hline [41] & $\begin{array}{l}\text { Numerical and } \\
\text { experimental }\end{array}$ & $\begin{array}{l}\text { Without runner/Cylindrical } \\
\text { basin }\end{array}$ & $\begin{array}{l}\text { Maximum efficiency of } 30 \% \text { when the outlet diameter is } \\
20 \% \text { of basin diameter }\end{array}$ \\
\hline$[40]$ & Experimental & With runner/Conical basin & $\begin{array}{l}\text { The turbine draws more energy near the outlet where the } \\
\text { higher tangential velocities are }\end{array}$ \\
\hline$[30]$ & Experimental & $\begin{array}{l}\text { With runner/Cylindrical and } \\
\text { Conical basin }\end{array}$ & $\begin{array}{l}\text { The efficiency increases with decreasing number of } \\
\text { blades. The turbine draws more energy near the outlet }\end{array}$ \\
\hline [22] & Numerical & Without runner/Conical basin & $\begin{array}{l}\text { As the basin diameter increases, the velocity of the vortex } \\
\text { decreases }\end{array}$ \\
\hline [43] & Numerical & $\begin{array}{l}\text { With runner/Cylindrical } \\
\text { basin }\end{array}$ & $\begin{array}{l}\text { The maximum efficiency } 40 \% \text { when } d / D \text { was } 0.2 \text {. Ideal } \\
\text { rotational velocity } 28-38 \mathrm{rpm} \text {. }\end{array}$ \\
\hline [20] & Numerical & Without runner/Conical basin & $\begin{array}{l}\text { The maximum velocity }(0.52 \mathrm{~m} / \mathrm{s}) \text { occurred when } D \text { was } \\
0.51 \mathrm{~m} \text {. The outlet diameter was within the range of } 14 \% \text { - } \\
18 \% \text { of. } D\end{array}$ \\
\hline$[42]$ & $\begin{array}{l}\text { Numerical and } \\
\text { experimental }\end{array}$ & Without runner/Conical basin & $\begin{array}{l}\text { As the outlet becomes larger, the flow is more turbulent } \\
\text { and causes more errors in the CFD model }\end{array}$ \\
\hline [21] & Numerical & $\begin{array}{l}\text { With runner/Cylindrical and } \\
\text { Conical }\end{array}$ & $\begin{array}{l}\text { The optimum position of the turbine is } 65 \%-75 \% \text { of the } \\
\text { height of the chamber (from the top). The conical basin } \\
\text { has a higher output power than the cylindrical basin }\end{array}$ \\
\hline [32] & Experimental & $\begin{array}{l}\text { With runner/Cylindrical } \\
\text { basin }\end{array}$ & $\begin{array}{l}\text { The efficiency increases with increasing number of } \\
\text { blades. Turbines with } 2 \text { and } 4 \text { flat blades were tested }\end{array}$ \\
\hline [31] & Experimental & $\begin{array}{l}\text { With runner/Cylindrical } \\
\text { basin }\end{array}$ & $\begin{array}{l}\text { Maximum efficiency } 35 \% \text { obtained using the aluminum } \\
\text { runner }\end{array}$ \\
\hline 33] & Experimental & $\begin{array}{l}\text { With runner/Cylindrical } \\
\text { basin }\end{array}$ & Generation power $60 \mathrm{~W}$ with a plant factor of $60 \%$ \\
\hline$[44]$ & $\begin{array}{l}\text { Numerical and } \\
\text { experimental }\end{array}$ & With runner/Conical basin & $\begin{array}{l}\text { Maximum efficiency } 78.65 \% \text { with } 6 \text {-blade secondary } \\
\text { runners. They do not specify the shape or number of } \\
\text { blades of the main runner }\end{array}$ \\
\hline [34] & Experimental & $\begin{array}{l}\text { With runner/Cylindrical } \\
\text { basin }\end{array}$ & $\begin{array}{l}\text { Maximum efficiency } 43 \% \text {. Efficiency increases with } \\
\text { decreasing number of blades }\end{array}$ \\
\hline [35] & Experimental & $\begin{array}{l}\text { With runner/Cylindrical } \\
\text { basin }\end{array}$ & $\begin{array}{l}\text { Maximum efficiency } 32.5 \% \text { with deflector plate of } 50 \% \\
\text { of the total area of the blades }\end{array}$ \\
\hline$[23]$ & Numerical & $\begin{array}{l}\text { without runner/Cylindrical } \\
\text { basin }\end{array}$ & $\begin{array}{l}\text { Efficiency increases when the vortex originates from the } \\
\text { conical surface to the outlet }\end{array}$ \\
\hline [45] & $\begin{array}{l}\text { Numerical and } \\
\text { experimental }\end{array}$ & $\begin{array}{l}\text { With runner/Cylindrical } \\
\text { basin }\end{array}$ & $\begin{array}{l}\text { The Shear Stress Transport model (SST) is the turbulence } \\
\text { model that best predicts the real performance of the } \\
\text { turbine using the VOF method }\end{array}$ \\
\hline$[36]$ & Experimental & $\begin{array}{l}\text { With runner/Cylindrical } \\
\text { basin }\end{array}$ & Maximum efficiency $22.24 \%$ with curved blades \\
\hline [24] & Numerical & $\begin{array}{l}\text { without runner/Cylindrical } \\
\text { basin }\end{array}$ & $\begin{array}{l}\text { The triangular inlet channel (viewed from the top) is the } \\
\text { most efficient because it tends to produce symmetric }\end{array}$ \\
\hline
\end{tabular}




\begin{tabular}{|c|c|c|c|}
\hline & & & $\begin{array}{l}\text { vortex that causes less imbalance radial force that is } \\
\text { responsible for the bending of the turbine shaft }\end{array}$ \\
\hline [46] & Numerical & With runner/Conical basin & Maximum efficiency $82 \%$ for curved blade runner \\
\hline [25] & Numerical & Without runner/Conical basin & $\begin{array}{l}\text { The highest velocity was achieved when the channel was } \\
\text { inclined } 60^{\circ} \text { downward }\end{array}$ \\
\hline [38] & Numerical & With runner/Conical basin & $\begin{array}{l}\text { Intensifier nozzles were found to strengthen vortex } \\
\text { formation in the conical basin and thus increase turbine } \\
\text { efficiency }\end{array}$ \\
\hline [39] & Numerical & With runner/Conical basin & $\begin{array}{l}\text { Runners with tilted blades are best suited for the position } \\
\text { near the bottom of the basin, while cross-flow blades are } \\
\text { recommended in the top position }\end{array}$ \\
\hline [47] & $\begin{array}{l}\text { Numerical and } \\
\text { experimental }\end{array}$ & $\begin{array}{l}\text { With runner/Cylindrical } \\
\text { basin }\end{array}$ & $\begin{array}{l}\text { The net head and turbine efficiency increased as the } \\
\text { volume flow rate increased }\end{array}$ \\
\hline [26] & $\begin{array}{c}\text { Numerical and } \\
\text { experimental }\end{array}$ & $\begin{array}{l}\text { With and Without } \\
\text { runner/Cylindrical basin }\end{array}$ & $\begin{array}{l}\text { An increase of } w / D \text { increases the mass flow, which causes } \\
\text { the water height to rise until overflow from the upper } \\
\text { walls of the basin occurs }\end{array}$ \\
\hline [37] & Experimental & $\begin{array}{l}\text { Without runner/Cylindrical } \\
\text { basin }\end{array}$ & $\begin{array}{l}\text { The efficiency increased polynomial with inlet flow rate } \\
\text { increments. Reducing the value of } S \text { will improve the } \\
\text { efficiency }\end{array}$ \\
\hline [28] & Numerical & Without runner/Conical basin & $\begin{array}{l}\text { The average velocity in curved inlet was greater than that } \\
\text { of the straight inlet }\end{array}$ \\
\hline [29] & Numerical & $\begin{array}{l}\text { Without runner/Cylindrical } \\
\text { and conical basin }\end{array}$ & $\begin{array}{l}\text { The largest tangential velocity }(1.55 \mathrm{~m} / \mathrm{s}) \text { was obtained } \\
\text { when the radius was } 0.22 \mathrm{~m} \text { and a wrap-around inlet was } \\
\text { used }\end{array}$ \\
\hline
\end{tabular}

Table 3. Numerical studies and parameters used.

\begin{tabular}{|c|c|c|c|c|c|}
\hline Author & Computational method & Turbulence model & $\begin{array}{l}\text { Solution } \\
\text { scheme }\end{array}$ & Type of analysis & $\mathrm{N}^{\circ}$ of elements \\
\hline $\begin{array}{l}{[41]} \\
{[20]}\end{array}$ & $\begin{array}{l}\text { FVM } \\
\text { FVM }\end{array}$ & RNG k- $\varepsilon$ & $\begin{array}{l}\text { Simple } \\
\text { Simple }\end{array}$ & Steady & 308,851 \\
\hline [21] & FVM & RNG k- $\varepsilon$ & Simple & Steady & 308,851 \\
\hline [22] & FVM & $k-\varepsilon$ & Simple & Steady & 53,788 \\
\hline [44] & FVM & Reynolds stress & Simple & Steady & 300,000 \\
\hline [23] & FVM & RNG k- $\varepsilon$ & & Steady & \\
\hline [45] & FVM & SST & & Unsteady & $2,201,000$ \\
\hline [46] & FVM & $\mathrm{k}-\varepsilon$ & & Steady & \\
\hline [28] & FVM & SST & Simple & Steady & 391,104 \\
\hline [29] & FVM & $k-\varepsilon$ & Simple & Unsteady & 901,779 \\
\hline [26] & FVM & SST & & Steady & $4,816,342$ \\
\hline
\end{tabular}

The water path, vortex height and, tangential velocity distribution are the most important variables used to analyze the behavior of the vortex when the runner is excluded. Without the runner, the objective is to increase the vortex height and tangential velocity, resulting in more available power. If the runner is included, inlet and outlet velocity triangles, torque, and efficiency are the control variables to analyze the system. The velocity triangles allow choosing the appropriate runner to take advantage of the available power, resulting in more torque and more efficiency.
Tab. 4 y 5 show the values of the main dimensions, efficiency, and outlet power for the cylindrical and conical basins used in some investigations. The dimensions were divided by the diameter basin $D$ to non-dimensionalize the results. The spaces in the tables indicate that the authors do not report those. Tab. 4 and 5 have some repeated authors because they used various models.

Table 4. Main dimensions for the cylindrical basin. Note: The authors do not report the value of. $\beta$

\begin{tabular}{l|c|c|c|c|c|c|c|c}
\hline Author & $\boldsymbol{d} / \boldsymbol{D}$ & $\boldsymbol{H} / \boldsymbol{D}$ & $\boldsymbol{w} / \boldsymbol{D}$ & $\boldsymbol{h} / \boldsymbol{D}$ & $\boldsymbol{L} / \boldsymbol{D}$ & $\boldsymbol{S} / \boldsymbol{D}$ & $\boldsymbol{\eta}[\%]$ & $\mathbf{P}_{\text {out }}[\mathbf{k W}]$ \\
\hline$[\mathbf{4 1}]$ & 0.20 & 1.00 & & & & & 30.0 & 0.060 \\
& 0.25 & 1.00 & & & & & 30.0 & 0.050 \\
& 0.30 & 1.00 & & & & & 30.0 & 0.045 \\
& 0.35 & 1.00 & & & & & 16.0 & 0.020 \\
{$[\mathbf{4 2}]$} & 0.05 & 1.88 & & & & & & \\
{$[\mathbf{2 1}]$} & & 1.42 & & & & & 27.8 & \\
{$[\mathbf{4 3}]$} & 0.20 & 0.30 & 0.40 & 0.30 & 1.00 & 0.2 & 30.0 & \\
{$[\mathbf{3 2}]$} & 0.05 & 1.40 & & & & & 15.1 & \\
{$[\mathbf{3 3}]$} & 0.06 & 1.88 & 0.23 & 0.63 & & 0.11 & & \\
{$[\mathbf{4 5}]$} & 0.20 & & 0.20 & 0.20 & & 0.10 & 35.4 & \\
{$[\mathbf{2 3}]$} & 0.14 & 1.00 & 0.30 & 0.30 & & 0.015 & &
\end{tabular}




\begin{tabular}{l|l|l|l|l|l|l|l|l} 
[36] & & 0.40 & & & & & 22.2 & 0.014 \\
{$[\mathbf{2 5}]$} & 0.40 & 0.90 & 0.25 & 0.25 & 0.57 & 0.13 & & \\
& 0.50 & 0.90 & 0.25 & 0.25 & 0.57 & 0.13 & & \\
{$[\mathbf{4 7 ]}$} & 0.60 & 0.90 & 0.25 & 0.25 & 0.57 & 0.13 & & 0.003 \\
{$[37]$} & 0.20 & & 0.2 & & & 0.1 & 50.0 & \\
& 0.18 & 1.25 & & & 1.28 & 0.1 & 26.0 & \\
& 0.18 & 1.25 & & & 1.28 & 0.16 & 22.0 & \\
& 0.18 & 1.25 & & & 1.28 & 0.22 & 18.0 & \\
& 0.18 & 1.25 & & & 0.96 & 0.10 & 28.0 & \\
& 0.18 & 1.25 & & & 0.64 & 0.10 & 26.0 & \\
{$[\mathbf{2 6}]$} & 0.18 & 1.25 & & & 0.32 & 0.10 & 25.0 & \\
{$[\mathbf{1 6}]$} & 0.16 & 1.00 & 0.2 & 0.2 & & & 10.46 & 3.300 \\
\hline
\end{tabular}

Table 5. Main dimensions for the conical basin.

\begin{tabular}{l|c|c|c|c|c|c|c|c|c|c}
\hline Author & $\boldsymbol{d} / \boldsymbol{D}$ & $\boldsymbol{H} / \boldsymbol{D}$ & $\boldsymbol{w} / \boldsymbol{D}$ & $\boldsymbol{h} / \boldsymbol{D}$ & $\boldsymbol{L} / \boldsymbol{D}$ & $\boldsymbol{S} / \boldsymbol{D}$ & $\boldsymbol{\beta}\left[{ }^{\circ}\right]$ & $\boldsymbol{\alpha}\left[{ }^{\circ}\right]$ & $\boldsymbol{\eta}[\%]$ & $\mathbf{P}_{\text {out }}[\mathbf{k W}]$ \\
\hline$[\mathbf{4 0}]$ & 0.15 & 0.83 & & & & & & 62.9 & & \\
& 0.15 & 1.25 & & & & & & 71.2 & & \\
& 0.15 & 1.67 & & & & & & 75.6 & & \\
& 0.15 & 2.08 & & & & & & & \\
{$[\mathbf{3 0}]$} & 0.17 & 1.42 & & & & & & & & \\
{$[\mathbf{1 6}]$} & 0.15 & 0.27 & 0.27 & 0.27 & 1.82 & 0.14 & & 32.5 & & \\
{$[\mathbf{3 3}]$} & 0.22 & 1.00 & 0.22 & 0.33 & & 0.11 & & 68.7 & & 0.150 \\
{$[\mathbf{4 4}]$} & & 1.50 & 0.50 & & & 0.25 & 170 & & 78.6 & \\
{$[\mathbf{4 8}]$} & 0.23 & 0.75 & 0.50 & 0.40 & & 0.25 & 170 & 62.6 & & 1.600 \\
{$[\mathbf{2 2}]$} & 0.30 & 1.00 & 0.30 & 0.30 & 1.80 & 0.15 & & 70.7 & & \\
{$[\mathbf{4 6}]$} & & 2.50 & 0.50 & 0.50 & 2.20 & 0.25 & 170 & & 71.0 & 0.014 \\
{$[\mathbf{3 8}]$} & 0.5 & 1.42 & 0.50 & 0.50 & 2.83 & 0.25 & & 71.4 & 42.4 & 0.033 \\
& 0.5 & 0.90 & 0.25 & 0.25 & 0.57 & 0.13 & & 74.4 & & \\
& 0.6 & 0.90 & 0.25 & 0.25 & 0.57 & 0.13 & & 77.4 & & \\
\hline
\end{tabular}

From Tables 4 and 5, the turbines being studied have efficiencies ranging between 17.5 and $78.65 \%$ and output powers between 0.0028 and $3.3 \mathrm{~kW}$. The ratio $d / D$ changes between 0.05 and 0.6 , the most using value is 0.15 . The maximum and minimum values of $H / D$ are 1.00 and 0.23 , respectively. The ratio $w / D$ changes between 0.2 and 0.5 . The maximum and minimum value of $h / D$ are 0.63 and 0.20 , respectively. The ratio $L / D$ changes between 0.57 and 3.9. The ratio $S / D$ is half of the relation $w / D . S, w$ and $h$ are some important parameters for effective vortex generation. The tangential velocity of water in the vortex basin depends on the inlet channel. The values of these parameters can be optimized by conducting extensive research on it to enhance the water flow in the vortex basin. The discharge, $d$, may have significant effects on flow that could alter the performance of the GWVHT, since its performance depends on the outlet volume flow of water. So, effects of $d$ can be examined in future studies.

\section{Challenges for development of GWVHT}

As any new turbine, the challenges of GWVHT development are immense. There are technical, environmental, economic, and policy challenges facing its implementation. The main challenges observed by the authors are

- Water resource assessment. Small streams and rivers can safely provide energy to run a SHP as GWVHT; nonetheless, there is commonly no flow gauges at these sites. This problem requires an investigation of streams and rivers characteristics: annual flow, depth and crosssection but global databases are not readily available to analyze the energy of the flow [26]. Selecting rivers or streams where the volume flow rate is relatively steady throughout the year is ideal to install a GWVHT.

- System design. The optimum design of GWVHT is an important technical challenge. GWVHT requires various components such as runner, inlet, basin, power converter, control system, and protection devices. Nevertheless, there is insufficient information for the design of these components. More studies must determine the optimal design of this turbine.

- Environmental impacts. GWVHT is known for low carbon energy production [25], however, they can produce downstream flow alterations from the flow reduction can include reduced aquatic biodiversity and barriers to fish migration [49]. These alterations have been advantageous because allow homogenously disseminate contaminants in water, aerate the water due to the high velocity of flow on the water surface, increase the head of evaporation so that water can reduce the temperature itself at rising temperatures in summer and, improve the dissolved oxygen concentration [50]. To reveal their effect on the natural flow of a specific river, ecosystem, and wildlife, there is a need for an investigation on the turbine usage for each installation.

- Economic feasibility. The cost of GWVHT installation is comparable to other micropower plants, like Francis, and cross flow turbine [51]. However, the installed cost depends on the final location. Some factors affect the cost: civil work, the complexity of the turbine design, the distance to the distribution area, and the system capacity [48]. Civil work represents about $40 \%$ of the total cost, turbine, and generator set $(30 \%)$, control equipment (22\%) and management cost (8\%) [52]. 
- Policy/regulatory framework. The rapidly growing demand for electricity, with the increase in the world population, presents an ideal environment for developing renewable energies, in particular small hydropower plants. However, this type of technology is more expensive than conventional power plants with fossil fuels [52]. To promote the development of renewable energies, the governments have financed investigations and developments of renewable energy technologies to make such energy a competitive one, establishing regulatory frameworks and policies to the renewable energy sector.

\section{Conclusions}

In modern societies, electricity is a basic need, and renewable resources, especially hydraulic resources, have a key role to play in supporting electricity-increased demand. Hydropower is the primary source of renewable energy; it contributes almost $60 \%$ of the global renewable supply, and nearly $20 \%$ of all electricity production. Small hydropower plants constitute a feasible and attractive solution to cover the increasing demand and to produce electricity in isolated regions. This facility can produce electricity operating in small rivers.

Among the different types of turbines, GWVHT allows to take advantage of locations that until now were impossible with conventional generation systems because requires a low hydraulic head. The GWVHT is a promising technology for application in developing countries where large hydroelectric power plants can run into financial, environmental, and social obstacles. Compared to existing hydropower technologies, the GWVHT is still premature and more research must optimize the basin, channel and runner geometry, to increase efficiency. The main findings of the numerical and experimental studies are:

- The most optimal relationship between the diameter of the circulation basin and the diameter of the discharge has been studied in numerical and experimental studies, but the authors have not reached the same conclusion. The most used value was 0.15 , but the ratio $d / D$ changed between 0.05 and 0.6 .

- Some studies have investigated the effect of different forms of the inlet, but made no changes to its dimensions. So the conclusion they reached is specific to the type of circulation basin used. The studies showed that the vortex formed by the use of an inlet with triangular geometry is more efficient, since it tends to produce a symmetric vortex pattern, which causes a smaller radial force. The most common channel used have a rectangular cross-section $(w \times h)$; the maximum and minimum value to $h / D$ are 0.63 and 0.20 and the ratio $w / D$ changes between 0.2 and 0.5 . The ratio $L / D$ changes between 0.57 and 3.9.

- $\quad$ Regarding the runner, the shape or number of blades has been varied, but the results of the investigations were contradictory. Therefore, it was not possible to obtain a generalized conclusion. In only one of the reported studies, the authors related the diameter and height of the circulation basin to the height and length of the inlet but did not use any runner, their conclusions could vary depending on the type of runner installed in the system.

- With reference to the position of the runner, it was possible to identify that for maximum energy extraction, the runner should be installed as close as possible to the outlet. - The studies showed that the conical basins are better than the cylindrical basins because the velocities reached in the vortex of the conical basins are higher. Additionally, there are no recirculation regions in the conical basin compared to cylindrical basins. These conclusions allow us to identify the best geometry, but not the dimensions of this geometry.

- The vortex height influences the efficiency of the turbine. Thus to increase the efficiency, it is necessary to maintain the vortex up to the outlet.

- Increasing the volume flow rate in the turbine increases the efficiency. However, there a limit to the increase in the volume flow rate. An excess flow prevent proper vortex formation or cause flow spillage. It is necessary a detailed study on the incoming flow.

- In a GWVHT, two of the main components: inlet channel and circulation basin can be constructed on-site using concrete or other construction materials. Although, it is possible to build transportable systems using aluminum or steel. These requirements are easier than the requirements for conventional systems, facilitating the construction of many of these plants along the path of a river. A GWVHT can also be integrated in a back flow canal of a water treatment station.

- Materials such as plastic, aluminum, or composite materials can be used to manufacture the turbine because they are lightweight materials. Changing the material will increase the power/weight ratio, its useful life and the modularity of the system. With a modular and lightweight turbine, the system can be transported and installed in remote areas with significant hydraulic potentials. It is important to develop simple geometries, which reduces civil works and employs basic workshops and local manufacturing to produce these systems at a lower cost.

- Several important simulation parameters such as mesh quality, convergence criteria, simulation type, element size, and number of elements are not shown in somes papers what makes difficult to compare the numerical results. Most of the numerical studies used Ansys as simulation software. The simple scheme to solve the governing equations was implemented in all studies. The most widely used turbulence model was the k- $\varepsilon$ model. - $\quad$ The GWVHT has efficiency ranging between 17 and $85 \%$. This wide range can be attributed to the different geometries, different methodologies used to measure the outlet power, and the equation used to calculate the available power. This information is not available in all investigations, therefore it is necessary to establish a methodology to conduct an adequate characterization.

The design of GWVHT still has many geometric configurations that have not yet been examined; so many ways are open for further exploration. Today, to develop better and lower-cost products, professionals are opting for optimization methodologies, which are used to conduct a more precise search for improvements. The optimization process employs a mathematical algorithm to select new designs iteratively in search of the optimal point. The designs of GWVHT will be improved while comparing different configurations using optimization techniques. Also, it is important to analyze which design factors are the most important and how their interactions affect the efficiency of the system to determine the optimum design.

\section{Acknowledgement}

The authors gratefully acknowledge the financial support provided by Convocatoria para el fortalecimiento de CTel en 
instituciones de educación superior (IES) públicas 2020 (Desarrollo de una turbina de vórtice gravitacional incorporando biomateriales para pequeñas centrales hidroeléctricas que contribuya a la diversificación de la matriz energética nacional), Universidad de Antioquia and Institución Universitaria Pascual Bravo.
This is an Open Access article distributed under the terms of the Creative Commons Attribution License.

\section{References}

1. Aguilera Folgueiras, J. A. Fuentes de energía y Protocolo de Kioto en la Evolución del Sistema Eléctrico Español, 2012.

2. Doman, L. EIA projects $28 \%$ increase in world energy use by 2040. US Energy Information Administration. 2017

3. Dudley, B. BP statistical review of world energy. BP Statistical Review, London, UK, accessed Aug, 6(2018), 00116. 2018

4. Rahman, M., Hong, T. J., Tang, R., Sung, L. L., \& Tamiri, F. B. M. Experimental study the effects of water pressure and turbine blade lengths \& numbers on the model free vortex power generation system. International Journal of Current Trends in Engineering \& Research (IJCTER), 2(9), 13-17, 2016.

5. IRENA, J. Renewable energy technologies: cost analysis series. Concentrating Solar Power. Comprehensive Renewable Energy, 3(2), 2012.

6. Howard, C. D., \& Stedinger, J. R. Hydroelectric Power and the Future. In Toward a Sustainable Water Future: Visions for 2050,2012, (pp. 234-242).

7. International hydropower association (2020). 2020 Hydropower Status Report.

8. Couto, T. B., \& Olden, J. D. (2018). Global proliferation of small hydropower plants-science and policy. Frontiers in Ecology and the Environment, 16(2), 91-100.

9. 이승오. (2019). World Small Hydropower development report 2019.

10. Timilsina, A. B., Mulligan, S., \& Bajracharya, T. R. (2018). Water vortex hydropower technology: a state-of-the-art review of developmental trends. Clean Technologies and Environmental Policy, 20(8), 1737-1760.

11. Goswami, D. Y., \& Kreith, F. (Eds.). (2007). Energy conversion. CRC press.

12. Valencia Balanta, J. Z. (2019). Revisión del potencial para aprovechamiento hidroeléctrico en el municipio de Timbiquí, Cauca (Doctoral dissertation, Universidad Santiago de Cali).

13. Williamson, S. J., Stark, B. H., \& Booker, J. D. (2014). Low head pico hydro turbine selection using a multi-criteria analysis. Renewable Energy, 61, 43-50.

14. Dhakal, S., Timilsina, A. B., Dhakal, R., Fuyal, D., Bajracharya, T. R., \& Pandit, H. P. (2014). Effect of dominant parameters for conical basin: Gravitational water vortex power plant. In Proceedings of IOE graduate conference (p. 381).

15. Mohanan, A. (2016). Power generation with simultaneous aeration using a gravity vortex turbine. International Journal of Scientific \& Engeenering Research, 7(2).

16. Guzmán, V. J. A., Glasscock, J. A., \& Whitehouse, F. (2019). Design and construction of an off-grid gravitational vortex hydropower plant: A case study in rural Peru. Sustainable Energy Technologies and Assessments, 35, 131-138.

17. Engenhariacivil.com (2018). Imagem do dia: Engenheiros belgas desenvolvem inovadora turbina de vórtice gravitacional capaz de $\begin{array}{llll}\text { fornecer energia } & \text { a } & 60 & \text { habitações. }\end{array}$ https://www.engenhariacivil.com/turbina-vortice-gravitacional

18. Mulligan, S., \& Hull, P. (2010). Design and optimisation of a water vortex hydropower plant. Undergraduate thesis, Inst. of Tech. Sligo, Sligo, Ireland.

19. Marian, G., Sajin, T., Florescu, I., Nedelcu, D. I., Ostahie, C. N., \& Bîrsan, C. (2012). The concept and theoretical study of micro hydropower plant with gravitational vortex and turbine with rapidity steps. Buletinul AGIR, 3, 219-226.

20. Dhakal, S., Timilsina, A. B., Dhakal, R., Fuyal, D., Bajracharya, T. R., \& Pandit, H. P. (2014). Effect of dominant parameters for conical basin: Gravitational water vortex power plant. In Proceedings of IOE graduate conference (p. 381).

21. Dhakal, S., Timilsina, A. B., Dhakal, R., Fuyal, D., Bajracharya, T. R., Pandit, H. P., ... \& Nakarmi, A. M. (2015). Comparison of cylindrical and conical basins with optimum position of runner: Gravitational water vortex power plant. Renewable and Sustainable Energy Reviews, 48, 662-669.
22. Sreerag, S. R., Raveendran, C. K., \& Jinshah, B. S. (2016). Effect of outlet diameter on the performance of gravitational vortex turbine with conical basin. J. Scientific \& Engineering Research, 7(4), 457463.

23. Chattha, J. A., Cheema, T. A., \& Khan, N. H. (2017, March). Numerical investigation of basin geometries for vortex generation in a gravitational water vortex power plant. In 2017 8th International Renewable Energy Congress (IREC) (pp. 1-5). IEEE.

24. Thapa, D., Mishra, A., \& Sarath, K. S. (2017). Effect of inlet geometry in the quality of vortex formed using vortex flow channel. Int. J. Mech. Eng. Technol, 8(5), 515-524.

25. Rehman, W., Ijaz, M., \& Munir, A. (2017, June). Designing of micro gravitational vortex turbine's vortex pool. In ASME Power Conference (Vol. 57618, p. V002T12A002). American Society of Mechanical Engineers.

26. Khan, N. H., Cheema, T. A., Chattha, J. A., \& Park, C. W. (2018). Effective basin-blade configurations of a gravitational water vortex turbine for microhydropower generation. Journal of Energy Engineering, 144(4), 04018042.

27. Wardhana, E. M., Santoso, A., \& Ramdani, A. R. (2019). Analysis of Gottingen 428 Airfoil Turbine Propeller Design with Computational Fluid Dynamics Method on Gravitational Water Vortex Power Plant. International Journal of Marine Engineering Innovation and Research, 3(3).

28. Havaldar, S., Gadekar, P. A., Baviskar, S. M., Jadhav, N. M., \& Inamdar, S. H. (2020). Analyzing Geometries for Inlet Flow Channels to Gravitational Water Vortex Chamber. no. August.

29. Velásquez, L and Rubio-Clemente, A \& Chica, E. (2020). Numerical analysis of the inlet channel and basin geometries for vortex generation in a gravitational water vortex power plant. 18th Inter Conference on Renew Energies and Power Quality.

30. Dhakal, S., Nakarmi, S., Pun, P., Thapa, A. B., \& Bajracharya, T. R. (2014). Development and testing of runner and conical basin for gravitational water vortex power plant. Journal of the Institute of Engineering, 10(1), 140-148.

31. Sritram, P., Treedet, W., \& Suntivarakorn, R. (2015, November). Effect of turbine materials on power generation efficiency from free water vortex hydro power plant. In IOP Conference Series: Materials Science and Engineering (Vol. 103, No. 1, p. 012018). IOP Publishing.

32. Power, C., McNabola, A., \& Coughlan, P. (2016). A parametric experimental investigation of the operating conditions of gravitational vortex hydropower (GVHP). Journal of Clean Energy Technologies, 4(2), 112-119.

33. Ayala, M., Benavides, H., \& Riba, C. (2016). Sistema de generación energía sumergible basado en un vórtice gravitacional con sifón para comunidades aisladas. Revista Técnica" energía", 12(1).

34. Rahman, M., Hong, T. J., Tang, R., Sung, L. L., \& Tamiri, F. B. M. (2016). Experimental study the effects of water pressure and turbine blade lengths \& numbers on the model free vortex power generation system. International Journal of Current Trends in Engineering \& Research (IJCTER), 2(9), 13-17.

35. Wichian, P., \& Suntivarakorn, R. (2016). The effects of turbine baffle plates on the efficiency of water free vortex turbines. Energy Procedia, 100, 198-202.

36. Kueh, T. C., Beh, S. L., Ooi, Y. S., \& Rilling, D. G. (2017, March). Experimental study to the influences of rotational speed and blade shape on water vortex turbine performance. In Journal of Physics: Conference Series (Vol. 822, No. 1, p. 012066). IOP Publishing.

37. Rahman, M. M., Hong, T. J., \& Tamiri, F. M. (2018). Effects of inlet flow rate and penstock's geometry on the performance of Gravitational Water Vortex Power Plant. In Proc. Int. Conf. Ind. Eng. Oper. Manag (Vol. 2018, pp. 2968-2976).

38. Srihari, P. S. V. V., Narayana, P. S. V. V. S., Kumar, K. S., Raju, G. J., Naveen, K., \& Anand, P. (2019, December). Experimental study on vortex intensification of gravitational water vortex turbine with 
novel conical basin. In AIP Conference Proceedings (Vol. 2200, No. 1, p. 020082). AIP Publishing LLC.

39. Ullah, R., Cheema, T. A., Saleem, A. S., Ahmad, S. M., Chattha, J. A., \& Park, C. W. (2019). Performance analysis of multi-stage gravitational water vortex turbine. Energy Conversion and Management, 198, 111788 .

40. Marian, M. G., Sajin, T., \& Azzouz, A. (2013). Study of micro hydropower plant operating in gravitational vortex flow mode. In Applied Mechanics and Materials (Vol. 371, pp. 601-605). Trans Tech Publications Ltd.

41. Wanchat, S., Suntivarakorn, R., Wanchat, S., Tonmit, K., \& Kayanyiem, P. (2013). A parametric study of a gravitation vortex power plant. In Advanced Materials Research (Vol. 805, pp. 811817). Trans Tech Publications Ltd.

42. Kueh, T. C., Beh, S. L., Rilling, D., \& Ooi, Y. (2014). Numerical analysis of water vortex formation for the water vortex power plant. International Journal of Innovation, Management and Technology, 5(2), 111.

43. Shabara, H. M., Yaakob, O. B., Ahmed, Y. M., Elbatran, A. H., \& Faddir, M. S. (2015). CFD validation for efficient gravitational vortex pool system. Jurnal Teknologi, 74(5).

44. Gautam, A., Sapkota, A., Neupane, S., Dhakal, J., Timilsina, A. B., \& Shakya, S. (2016, August). Study on effect of adding booster runner in conical basin: gravitational water vortex power plant: a numerical and experimental approach. In Proceedings of IOE Graduate Conference (pp. 107-113).

45. Nishi, Y., \& Inagaki, T. (2017). Performance and flow field of a gravitation vortex type water turbine. International Journal of Rotating Machinery, 2017.

46. Dhakal, R., Bajracharya, T. R., Shakya, S. R., Kumal, B., Kathmandu, N., Khanal, K., ... \& Ghale, D. P. (2017, November). Computational and experimental investigation of runner for gravitational water vortex power plant. In Proceedings of a meeting held (Vol. 5, p. 8).
47. Nishi, Y., Suzuo, R., Sukemori, D., \& Inagaki, T. (2020). Loss analysis of gravitation vortex type water turbine and influence of flow rate on the turbine's performance. Renewable Energy, 155, 1103-1117.

48. Dhakal, R., Nepal, A., Acharya, A., Kumal, B., Aryal, T., Williamson, S. J., ... \& Devkota, L. (2016, November). Technical and economic prospects for the site implementation of a gravitational water vortex power plant in Nepal. In 2016 IEEE International Conference on Renewable Energy Research and Applications (ICRERA) (pp. 1001-1006). IEEE.

49. Hennig, T., \& Harlan, T. (2018). Shades of green energy: geographies of small hydropower in Yunnan, China and the challenges of over-development. Global Environmental Change, 49, 116-128.

50. Rahman, M. M., Tan, J. H., Fadzlita, M. T., \& Muzammil, A. W. K. (2017, July). A Review on the development of Gravitational Water Vortex Power Plant as alternative renewable energy resources. In IOP Conference Series: Materials Science and Engineering (Vol. 217, No. 1, p. 012007). IOP Publishing.

51. Dhakal, R., Chaulagain, R. K., Bajracharya, T., \& Shrestha, S. (2015). Economic feasibility study of gravitational water vortex power plant for the rural electrification of low head region of nepal and its comparative study with other low head power plant. In Conference proceeding of the 11th international conference on ASEAN knowledge networks for the economy, society, culture, and environmental stability, Kathmandu.

52. Elbatran, A. H., Yaakob, O. B., Ahmed, Y. M., \& Shabara, H. M. (2015). Operation, performance and economic analysis of low head micro-hydropower turbines for rural and remote areas: A review. Renewable and Sustainable Energy Reviews, 43, 40-50.

53. Schilling, M. A., \& Esmundo, M. (2009). Technology S-curves in renewable energy alternatives: Analysis and implications for industry and government. Energy policy, 37(5), 1767-1781. 